\title{
Personalized Temporal Trading Functionalities Engaged in Calendar Market Anomalies: Empirical Evidences from the 2007 and 2009 Financial Crises
}

Vasiliki A Basdekidou*

Special Research Fund Account (ELKE) Aristotle University of Thessaloniki, Greece

\begin{abstract}
In volatile markets -like the calendar market anomalies- institutions, traders and speculators constantly search for predictable security's price action patterns; and their trading plans disturb security prices when they attempt to exploit the uprising trading opportunities. Generic forecasting patterns once become known to public are, therefore, unlikely to win for long periods of time and they will self-destruct when discovered by a large number of traders and speculators. Therefore, this gives rise to non-stationarities in the time series of financial returns and complicates formal tests and evidences of market efficiency, market anomalies and the search for successful and profitable forecasting approaches. Obviously, the need for adapted (i.e. no generic) strategies in trading the calendar market anomalies is apparent. This personalization is complicated and is referred to particular calendar market anomaly (seasonality), to trading instrument characteristics (e.g. beta functionality), and to the traders' profile (investors, swing traders, intraday speculators, etc.). Hence, in the calendar market anomalies domain, the personalized (adaptive) temporal dynamic approaches could improve trading returns by incorporating temporal trading functionalities. The main target of this paper is to investigate, analyze and document the personalized trading functionalities enclosed in calendar market anomalies. These functionalities are characterized as temporal because of the "time" function involved by default in calendar market anomalies. In particular this article is focused on the identification of monthly calendar anomalies on the Greek and Bulgarian stock markets. Empirical evidences, before and after the 2007 and 2009 financial crises, are presented in support of the hypothesis that small and less liquid markets tend to exhibit market anomalies. In the case of Greece these anomalies are so strong that they are not influenced by the recent crises. Empirical evidences also show that crises may change the long-run calendar anomalies trading functionalities and therefore lead to an improved Market efficiency as a short-run effect. Paper's innovation is related to the introduction and discussion of the personalized (adapted) temporal trading functionalities encapsulated in markets inefficiency, as far as the calendar markets anomalies is concern. Actually, the presented analysis, in this article, enhances the existing portfolio of approaches and knowledge about the impact of financial crises on real firm behavior during the calendar market anomalies periods.
\end{abstract}

Keywords: Efficient market hypothesis; Calendar market anomalies; Temporal trading functionalities; Personalized trading; Liquidity management; Financial crisis

\section{Introduction}

A market anomaly (or market inefficiency) is a price and/or rate of return distortion on a financial market that seems to contradict the efficient-market hypothesis [1-3]. The market anomaly, as empirical observational evidence, is referred to: Structural factors (such as unfair competition, lack of market transparency, regulatory actions, etc.); Behavioural biases by economic agents [4-6]; and Calendar effects, such as the "January effect" [7-9].

Market anomalies, as hypothetical theoretic evidences, are related to the economic fundamentals of the security (fundamental anomalies); to technical trading rules (technical anomalies); and to economic calendar events (calendar anomalies). Fundamental anomalies include value effect, small-cap effect (low P/E stocks and small cap companies do better than index on an average) and the Low-volatility anomaly, technical anomalies include momentum effect [10], while calendar anomalies involve patterns in stock returns from year to year, month to month, day to day [11-13].

According to the so called efficient-market hypothesis, regulated security markets are viewed as efficient ${ }^{1}[1-3,7]$ and there is a logical justification in that respect. These markets have competitive structure,

${ }^{1} \mathrm{~A}$ security market is efficient if at all times prices of all securities are equal to their investment value reflecting fully and immediately all of the information available. their transaction costs are minimal, their infrastructure is well organized and the information is usually equally accessible to all market agents. In light of these circumstances, it seems only logical to expect that these markets should be efficient.

Therefore, whenever a security market is being analyzed in trading strategies, one of the most frequently studied aspects concerns the possible availability of market anomalies. The empirical study of such market anomalies represents a constant interest and researchers often refer to it whenever there are new empirical observations accumulated. The reason is that the identification of market anomalies implies that, for some reason, the respective security market is not efficient, and the lack of market anomalies would confirm the efficient-market hypothesis.

Besides the theoretical problem for the availability or the lack of market efficiency there is also another reason that makes anomalies

*Corresponding author: Vasiliki A Basdekidou, Special Research Fund Account (ELKE) Aristotle University of Thessaloniki, Greece, Tel: +302310996000; E-mail: Vasiliki.Basdekidou@gmail.com

Received July 5, 2016; Accepted November 28, 2016; Published November 30 2016

Citation: Basdekidou VA (2016) Personalized Temporal Trading Functionalities Engaged in Calendar Market Anomalies: Empirical Evidences from the 2007 and 2009 Financial Crises. J Bus Fin Aff 5: 225. doi: 10.4172/2167-0234.1000225

Copyright: @ 2016 Basdekidou VA. This is an open-access article distributed under the terms of the Creative Commons Attribution License, which permits unrestricted use, distribution, and reproduction in any medium, provided the original author and source are credited. 
a focus of interest. When market anomalies are being observed, they are typically related to the existence of unfair competition, regulatory restrictions, and issues with relevant information access, structural factors or behavioral reactions not related to information about stock fundamentals. At the same time, anomalies, should they persist long enough, could give rise to trade strategies that investors might make use of. On the one hand, they indicate some market imperfections, and, on the other, they could represent a commercial interest for investors.

Despite of the theoretical arguments in favor of the efficient-market hypothesis for the regulated security markets there are numerous evidences that market anomalies existed in different periods on many markets. This is an empirical fact and it could be expected that if there are anomalies smaller and less liquid markets will tend to exhibit more market anomalies than larger and more liquid ones.

The focus of the present study is on the calendar effects on the Greek and the Bulgarian stock exchanges. Unlike many of the developed and a number of the emerging markets, these two stock markets have been relatively poorly studied with respect to their empirical characteristics. This justifies a study trying to bring in additional arguments for or against stock market efficiency from the point of view of comparatively small and less liquid markets such as the Greek and the Bulgarian ones.

The period under investigation includes the last two financial crises $^{2}$, which influenced and had a significant impact on both these markets. This further allows for an additional research perspective which deals with the question - how and in what way was the efficiency of these two markets influenced by the crises?

\section{Articles innovation note}

Paper's innovation is referred to the introduction and discussion of the personalized (adapted) temporal trading functionalities encapsulated in markets inefficiency, as far as the calendar market anomalies is concern. Actually, the presented analysis adds to the portfolio of approaches and knowledge about the impact of financial crises on real firm behaviour.

The rest of the paper is organized as following. The "Calendar Market Anomalies" section provides literature review on calendar anomalies. Then, the "Methodology and Data" section explains the methodology of the study and the data used in it. Following, the section "Empirical Observational Results" presents and discusses the main results obtained on the basis of the application of the chosen methodology. Thereafter, the "Discussion" section interprets, explains and describes paper's findings and the new understandings of the trading opportunities involved in market anomalies; and finally in "Conclusions" section a synopsis of the introduced methodology and innovation is presented and discussed.

\section{Calendar market anomalies}

A number of calendar temporal market anomalies, related to the monthly returns of the underlined securities, were discussed so far in the economic literature. These cases were analyzed in detail for the US markets $[14,15]$; the developed markets $[9,16,17]$; the emerging markets [18-21]; and the transitional economies markets, such as those of Poland, Romania, Hungary and Slovakia [22-24].

${ }^{2}$ The two crises are the following: the first one is the international financial crisis that started at the end of 2007, due to the subprime mortgage crisis on the American market. It practically spread out to all international markets. The second one is the sovereign debt crisis within the Eurozone, which began during the fall of 2009 and spread out mainly to the countries from the so-called EU periphery (Greece, Italy, Portugal, Spain, Ireland), but also to the rest of the EU countries to a varying degree.
The most widespread calendar anomalies are the so-called: "Weekend effect", "January effect", "Halloween effect", "November effect" and "December effect". Obviously, these effects could not be identified on all markets and at all times [25,26]. In particular, the "January effect" is a calendar anomaly which manifests itself through higher stock returns in the month of January relative to the other months of the year. This phenomenon has been well documented by empirical data in numerous studies. It was first identified in [14] - in their research they find that in the period from 1904 till 1974 the mean return for the month of January for the New York Stock Exchange was three percentage points higher than the mean return for the other months. In fact, more than a third of the annual return was realized in the month of January in particular. Another research on the New York Stock Exchange [15] indicates that most probably this effect was mainly due to low-cap companies' shares, since, on average, half of their annual returns have been accumulated in the month of January.

Later on, a lot of research has documented that such an anomaly could be observed not only on the American market. It was identified on other developed markets, too - in Japan [16], in Canada [17], Great Britain, Italy, Hong Kong [9]. It was also identified on a number of emerging markets such as Malaysia [18] and Turkey [19], as well as in transitional economies such as those of Poland, Romania, Hungary, and Slovakia [22].

As for the Greek stock market, economic literature offers inconsistent results. On the one hand, $[25,27,28]$, ascertain a powerful "January effect", whereas Floros [29] finds no such effect. The reason for this discrepancy is in the different periods that researchers analyze. In the context of the present study it should be taken into account that the time series considered by these researchers stretch at latest until year 2002 .

The body of economic research offers various possible explanations to the "January effect", and yet none of them has been commonly accepted. Most frequently, the phenomenon is being explained through the behavior of institutional investors who do "tax-loss selling". In other words at the end of the tax year they sell their loss-making positions. The aim of such behavior is to realize capital losses at the end of the tax year that could compensate for the capital gains from the profit-making positions, so that investors could achieve a particular tax effect. This type of behavior at the end of the year causes an increase of the supply of shares that have registered poor performance over the year, which results in an additional tendency for reduction of their prices. Such a decline is caused by calendar reasons (the tax-year end), and not by fundamental factors or some new information. Then, at the beginning of the next year (in January), the pressure on the supply side and on prices of these shares, respectively, dies out and they manage to realize abnormal high returns since they recover their fair market price.

The tax effect sought is one plausible explanation and it has been accepted by many researchers, but, at the same time, it could not be the only explanation. A lot of research indicates that the "January effect" has also been observed on markets as the Canadian one, where there is no capital gains tax [17], or as the Japanese one, where netting capital gains with capital losses is not allowed [16]. Another plausible explanation of the "January effect" is also the release of new information. For many companies, the first announcements for the financial results for the last fiscal year are released in January [14]. Yet another possible explanation is the existence of a positive relationship between risk premium and portfolio returns in January [30].

Similarly to the "January effect", the so-called "December effect" is a market anomaly according to which stock returns in December are 
systematically higher compared to other months of the year. This effect is most commonly observed during the last trading days or during the last week of the year, and is, therefore, often referred in the literature as "the turn-off-the-year effect". This anomaly has been identified on markets such as the Australian [31], the Indian [32], the ones in Belgium, Canada, Japan, Switzerland [9].

The explanation for this phenomenon has also been sought in several directions. One of them points out tax arguments just as with the "January effect". If it is rational for investors to try to liquidate positions with losses in December in order to compensate capital gains, it is also rational for them in December to delay the selling of stocks that have generated capital gains throughout the year. By postponing the selling of such stocks for several days, investors could delay paying taxes for an entire fiscal year, and therefore they usually restrain from such selling. In this way, the supply of stocks, which have generated capital gains throughout the year, is weak in December in particular which in turn leads to an additional tendency for increasing their prices.

Some other explanations to the "December effect" focuses on making investments awaiting the "January effect", or a targeted restructuring for reporting and accounting purposes of institutional investors' portfolios. It is often the case that at the end of a particular reporting period many portfolio managers aim to fill in their portfolios with stocks that have performed well during the past period. This could be observed by quarters when reporting has that frequency, but it is most well observed at the end of the year.

It should also be noted that monthly calendar anomalies have been observed not only in the months of January and December. Although much rare, such anomalies have been identified in other months as well. For example, some markets have documented anomalies related to the month of November [33-35].

Yet another calendar market anomaly is the so-called "Halloween effect". That is the name of the phenomenon under which stock returns are significantly higher for the period November-April compared to the period May-October. If that is actually true, it would be profitable for financial investors to buy shares at the end of October ${ }^{3}$ and sell them at the beginning of May. Therefore, sometimes such a strategy is referred to as "sell in May and go away".

This effect has also been observed on a number of markets. The first investigation of the problem was conducted by Bouman, and Jacobsen [36]. In their paper they present evidences that the "Halloween effect" was present in 36 of the 37 countries they studied for the period from 1970 till 1998 (18 countries) and for the period from 1988 till 1998 (19 countries). One of the 36 markets that displayed the effect was the Greek market between 1970 and 1998. The authors also found out that the effect was the strongest on the European stock markets. Later on, those same countries have been studied in Andrade et al. [37], and they arrived at the conclusion that the effect also persisted during the years following the period analyzed by Bouman and Jacobsen [36]. The analysis of Andrade et al. [37] indicates the availability of the "Halloween effect" in these countries also for the period up to April, 2012.

The effect is manifested in the fact that the mean return for the six months from November till April was about 10 percentage points higher than during the other six months of the year, and such size of

\footnotetext{
${ }^{3}$ The famous holiday "Halloween" is celebrated at the end of October in the USA. This coincidence gives the name to the aforementioned effect.
}

the effect allowed for the application of a successful trading strategy. What is more, the authors also demonstrate that the effect manifested itself not only in aggregation for the market as a whole, but also in separate classes of shares (e.g. according to size or according to book value-price ratio).

For the Greek market in particular, the availability of the "Halloween effect" has been studied in Siriopoulos, and Giannopoulos [38]. The authors find such effect but explain it by atypical, "extraordinary" returns during specific months.

There is no commonly accepted view with regard to what factors could actually cause the "Halloween effect". The economic literature offers mainly two hypotheses. According to Bouman and Jacobsen [36] this seasonal effect is caused by the holiday season for the market participants. Kamstra et al. [39], on the other hand, offer an explanation related to behavioral reactions. By analyzing the geographical location of markets, controlling for other factors, they find a correlation between returns' cycles and the duration of the light part of day, which is shorter during the fall-winter season. Thus, they arrive at the hypothesis for the possible influence of the duration of the light part of the day on the mood of some of the investors, on their readiness to take on risk, and on their ability to estimate that risk. This in turn could cause cyclic recurrence in their behavioral reactions which follows the change of the fall-winter season by the spring-summer season.

Finally, the "Weekend effect" is a phenomenon in financial markets in which stock returns on Mondays are often significantly lower than those of the immediately preceding Friday. Some theories that explain this effect attribute the tendency for companies to release bad news on Friday after the markets close to cause depressed stock prices on Monday. Others state that the "Weekend effect" might be linked to short selling, which would affect stocks with high short interest positions. Alternatively, the effect could simply be a result of traders' fading optimism between Friday and Monday [40-44].

The weekend effect has been a regular feature of stock trading patterns for many years. For example, according to a study by the Federal Reserve, prior to 1987 there was a statistically significant negative return over the weekends. However, the study did mention that this negative return had disappeared in the period from post-1987 to 1998 . Since 1998, volatility over the weekends has increased again, and the phenomenon of the weekend effect remains a much debated topic.

In this paper, I document regularities in trading patterns of individual and institutional investors related to the day of the week. I find a relative increase in trading activity by individuals on Mondays. In addition, there is a tendency for individuals to increase the number of sell transactions relatively to buy transactions, which might explain at least part of the "Weekend effect".

\section{Methodology and Data}

The study of the calendar effects on the Greek and the Bulgarian stock markets has been performed through the application of regression analysis. The following econometric models have been specified, based on the market indices of the Athens Stock Exchange (Athens) and the Bulgarian Stock Exchange (Sofia):

$$
\begin{aligned}
& \mathrm{R}_{\mathrm{t}}=\sum_{1}^{12} \mathrm{c}_{\mathrm{i}} \mathrm{D}_{\mathrm{it}}+\mathrm{u}_{\mathrm{t}} \\
& R_{t}=c_{0}+c_{1} D H t+u_{t}
\end{aligned}
$$


The following symbols have been used:

$R_{t}:$ return in period $\mathrm{t}$;

$D_{i t}$ : dummy variable which takes the value 1 for the $\mathrm{i}^{\text {th }}$ month and 0 otherwise;

$D H_{t}$ : dummy variable which takes the value 1 if the relevant month falls within the November-April period and 0 if the relevant month falls within the May-October period;

\section{$C_{i}$ : parameters of the model subject to estimation;}

$u_{t}$ : residual, random error of the model.

The applied models are standard for the study of calendar effects. These models and their modifications have been used, for example, by $[26,31,32]$ for the monthly calendar effects, and by Siriopoulos, and Giannopoulos [38] for the "Halloween effect".

These models have the following logic. Model (1) reflects the influence of returns in different months. It allows for testing the null hypothesis that there are no months whose influence on market return is statistically different from the other months of the year. The alternative hypothesis is that there are such months, whose return, other things being equal, is systematically different from the return for the other months of the year.

From a formal point of view, the null hypothesis is that $C_{1}=C_{2}=\ldots$ $=C_{12}$, and the alternative is that it is not true - not all coefficients are equal. If the null hypothesis is rejected, then the returns exhibit monthof-the-year effect. In this case during the respective month there is a recurring over time, statistically different return in comparison to returns in the other months. So, a monthly calendar effect is being observed, while the size and direction of this effect are determined by the respective parameter $C_{i}$ for the particular month.

Model (2), on the other hand, reflects through the variable $\mathrm{DH}_{t}$, the aggregated influence of returns for the months from November till April on the return of the market. It tests the null hypothesis that during the period between November and April return does not significantly differ from the return during the period from May to October, i.e. there is no "Halloween effect" observed. The "Halloween effect" will be observed if the return during the periods November-April is systematically different and higher than the return during the periods MayOctober. The constant term in the regression equation $C_{0}$ corresponds to the mean return for the months from May to October, while the parameter $C_{1}$ corresponds to the difference between the return for the months from November to April and the return for the months from May to October. From the point of view of the formal apparatus, the null hypothesis is that $C_{1=}$, and the alternative is that $C_{1}$ is a positive number.

The data related to returns on the Greek market is calculated on the basis of the GD Index, which is the main composite index of the Athens Stock Exchange. The data regarding returns on the Bulgarian stock market is calculated on the basis of the main index of the Bulgarian Stock Exchange (SOFIX). Both indices are capitalization-weighted, they are calculated and officially published by the stock exchanges in Athens (for the Greek market) and in Sofia (for the Bulgarian market). Monthly data has been used and in the graphs and tables later in the text, monthly returns for the Greek market are indicated by GDMR, and monthly returns for the Bulgarian market are indicated by SOFIXMR. The period under investigation is Jan.1991-Dec.2014 for the Greek market and Oct. 2000-Dec. 2014 for the Bulgarian market since the later is a very young one and this is the longest possible data period.
Figures 1 and 2 show returns by months for the Greek and the Bulgarian stock markets, respectively. The graphs are organized in such a way that they indicate what the return for the respective month was for all the years included into the analyzed period. As it is well seen in these graphs, there is justification to analyze the possibility of a probable calendar market anomaly. For the Greek market the months of January, March, June, and December apparently often register higher returns compared to the other months of the year. The month of May is characterized by significantly low returns. For the Bulgarian market the months of January, February, July, and December stand out with higher returns. The question is how systematic those differences are - are they random or do they have a systematic nature, i.e. are they statistically significant.

Personalized trading is referred to adapted trading approaches as far as the trading instruments (e.g. stocks or 3x leveraged ETFs; bonds, Forex), time-frame (e.g. 30-min; daily; weekly) and strategies (e.g. intraday or swing trading) is concern [10-13]. Also, the term "Temporal Trading Functionalities, TTF" was introduced for the first time in financial literature by Basdekidou and Styliadou in [10-13].

Personalized temporal trading functionalities involved in calendar market anomalies and affects markets inefficiency as far as the various "effects" is concern. These "effects" are well known to traders and speculators, so stable forecasting patterns are, therefore, unlikely to persist for long periods of time and have been already self-destructed because they have been "discovered" by a large number of traders and speculators. Therefore, this gives rise to non-stationarities in the time series of financial returns and complicates formal tests and evidences of market efficiency, market anomalies and the search for successful

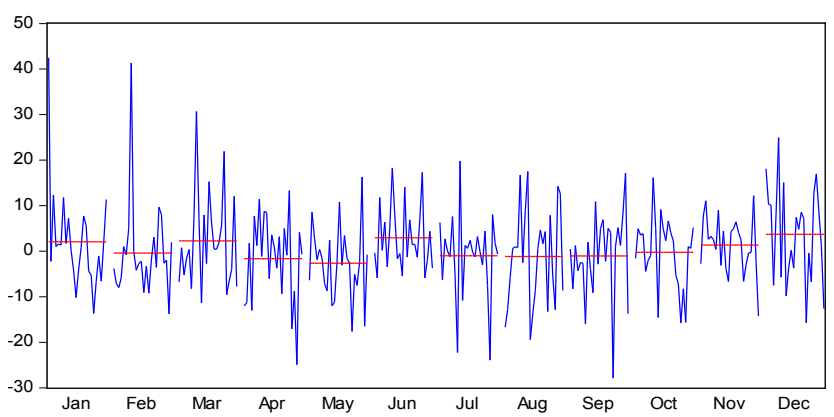

Data source: Athens Stock Exchange (Athens, GR)

Figure 1: Stock market returns (\%) in Greece by months: 1991-2014.

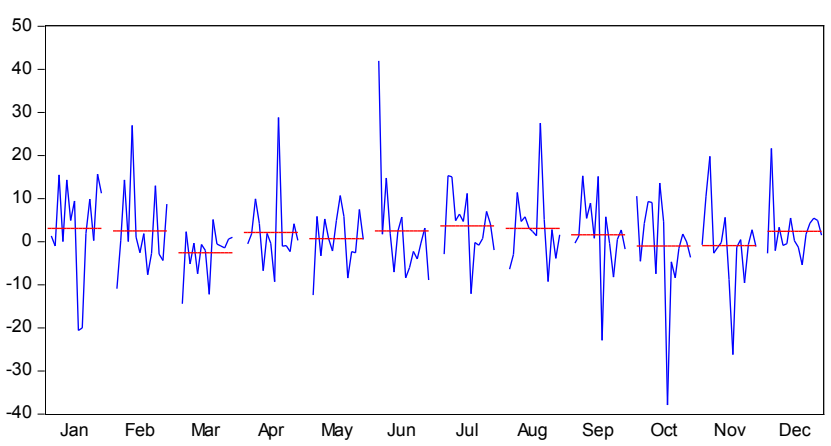

Data source: Bulgarian Stock Exchange (Sofia, BG).

Figure 2: Stock market returns (\%) in Bulgaria by months: 2000-2014 
forecasting approaches. In this domain, recent bibliography introduces temporal price action patterns which can be easily adapted to support particular personalized regulations, forms and plans [10-13]. Hence, the personalized (adaptive) temporal dynamic approaches could improve trading market anomalies returns by incorporating temporal trading functionalities.

\section{Empirical observational results}

Each of the Models (1) and (2) has been evaluated in three different time periods. For the Greek market those are the periods 1.199111.2007, 1.1991-9.2009, and 1.1991-12.2014, respectively. The point of having these three periods is to capture the influence of both crises; the international financial crisis and the debt crisis in the Euro zone. The international financial crisis hit the Greek market after December, 2007, and the debt crisis started in October, 2009. Therefore, by separately analyzing those periods before the beginning of the aforementioned crises, together with the period from 1.1991 till 12.2014 as whole, there is the opportunity to make comparisons and draw the respective conclusions with regard to the possible influence of the crises on market efficiency.

The same logic has been applied to the selection of timeframes for the Bulgarian market. The following periods have been analyzed: 10.2000-11.2007, 10.2000-9.2009, 10.2000-12.2014 taking into account the fact that the month of October, 2000 is the earliest period for which there is official data for the SOFIX index.

The possible influence of the crises on the efficiency of the markets could be analyzed by another method as well. For example, Siriopoulos, and Giannopoulos [38], as well as Dash et al. [32], introduce into the equations additional dummy variables for months where unusually large price changes are observed. This allows for direct isolation of the influence of these observations and for a separate analysis from the rest of the data.

This approach, however, is purely technical and presupposes a certain degree of subjectivism in making the decision according to which observations should be considered as "outliers" and should be isolated from the main sample respectively. If just the "large" (following some formal criteria) deviations are isolated from the algorithm for estimation of the parameters, it could also happen that data might be isolated, which is not part of the period of the respective crisis and was not caused by it, or the sample could keep such data which was caused by the crisis, but did not register large enough deviations. In this study, the exact time and the reasons for the crises are well known, so the analysis of separate periods in general, by taking into account the crises, is more justified from an economic stance.

Before evaluating the parameters of the respective models, the data about returns on the Greek stock market (GDMR) and about returns on the Bulgarian stock market (SOFIXMR) have been tested for stationary. This has been done by applying the Dickey-Fuller test and the results are presented in Table 1.

As the results indicate, the coefficients before the lag values DGMR(-1) and SOFIXMR(-1) are statistically significant and negative. In this way, the hypothesis for non-stationarity is rejected with a very high confidence level (over 99\%) for both markets.

Table 2 presents the results of the econometric estimation of model (1) for the Greek market. It demonstrates, for each of the three analyzed periods, the values of the estimated coefficients for the relevant months and student's t-statistic, which is used to estimate the statistical significance of the coefficients.

The empirical results demonstrate that within the three periods there is justification to reject the null hypothesis, i.e. there is the justification to accept that there is a calendar anomaly. If we analyze the period before the two crises, such anomaly is observed for the months of January and December. In both cases the parameters of the model for the respective months turn out to be positive and statistically significant. The parameter for the month of January is significant at a $95 \%$ confidence level, and the parameter for the month of December is significant at a $99 \%$ confidence level. Consequently, during a period of

\begin{tabular}{|c|c|c|c|c|}
\hline \multicolumn{5}{|c|}{ GDMR, No. of Observations: 287} \\
\hline Variable & Coefficient & Std. Error & t-Statistic & Prob. \\
\hline $\operatorname{GDMR}(-1)$ & -0.86556 & 0.056708 & -15.26358 & 0 \\
\hline $\mathrm{C}$ & 0.145228 & 0.526153 & 0.276019 & 0.7827 \\
\hline R-squared & 0.449783 & Mean dependent var & & -0.19202 \\
\hline Adjusted R-squared & 0.447852 & S.D. dependent var & & 11.9851 \\
\hline S.E. of regression & 8.905727 & Akaike info criterion & & 7.21821 \\
\hline Sum squared resid & 22603.91 & Schwarz criterion & & 7.243712 \\
\hline Log likelihood & -1033.81 & Hannan-Quinn criter. & & 7.228431 \\
\hline F-statistic & 232.977 & Durbin-Watson stat & & 1.952941 \\
\hline Prob(F-statistic) & 0 & & & \\
\hline \multicolumn{5}{|c|}{ SOFIXMR, nbr of observations 170} \\
\hline Variable & Coefficient & Std. Error & t-Statistic & Prob. \\
\hline SOFIXMR(-1) & -0.75667 & 0.074606 & -10.14223 & 0 \\
\hline $\mathrm{C}$ & 1.009249 & 0.70354 & 1.434531 & 0.1533 \\
\hline R-squared & 0.379764 & Mean dependent var & & -0.05334 \\
\hline Adjusted R-squared & 0.376072 & S.D. dependent var & & 11.48355 \\
\hline S.E. of regression & 9.070755 & Akaike info criterion & & 7.259683 \\
\hline Sum squared resid & 13822.8 & Schwarz criterion & & 7.296575 \\
\hline Log likelihood & -615.073 & Hannan-Quinn criter. & & 7.274653 \\
\hline F-statistic & 102.8648 & Durbin-Watson stat & & 2.020519 \\
\hline Prob(F-statistic) & 0 & & & \\
\hline
\end{tabular}

Data source: The respective stock exchanges. 


\begin{tabular}{|c|c|c|c|c|c|c|}
\hline \multirow{2}{*}{ Variable } & \multicolumn{2}{|c|}{ Jan. 1991-Nov. 2007} & \multicolumn{2}{|c|}{ Jan. 1991-Sept. 2009} & \multicolumn{2}{|c|}{ Jan. 1991-Dec. 2014} \\
\hline & Coefficient & t-statistics & Coefficient & t-statistics & Coefficient & t-statistics \\
\hline D1 & $4.0532^{* *}$ & 1.9286 & 2.6288 & 1.2760 & 2.0510 & 1.0833 \\
\hline D2 & -0.4617 & -0.2197 & -0.0913 & -0.0443 & -0.4216 & -0.2227 \\
\hline D3 & 2.5125 & 1.1955 & $3.7035^{\star}$ & 1.7977 & 2.2748 & 1.2016 \\
\hline D4 & -0.2641 & -0.1257 & 0.4182 & 0.2030 & -1.6386 & -0.8655 \\
\hline D5 & -1.7759 & -0.8450 & -2.7832 & -1.3509 & -2.6505 & -1.4000 \\
\hline D6 & 3.2424 & 1.5428 & 3.1950 & 1.5508 & 2.9466 & 1.5564 \\
\hline D7 & -0.1816 & -0.0864 & -0.0887 & -0.0431 & -0.9994 & -0.5279 \\
\hline D8 & -1.3446 & -0.6398 & -1.4842 & -0.7204 & -1.1721 & -0.6191 \\
\hline D9 & -0.9515 & -0.4527 & -2.2693 & -1.1015 & -1.0331 & -0.5457 \\
\hline D10 & 1.9994 & 0.9514 & 1.4925 & 0.7052 & -0.2494 & -0.1317 \\
\hline D11 & 2.7684 & 1.3173 & 2.2459 & 1.0611 & 1.3340 & 0.7046 \\
\hline D12 & $5.2826^{* * *}$ & 2.4385 & $3.7983^{*}$ & 1.7945 & $3.6919^{* *}$ & 1.9501 \\
\hline
\end{tabular}

Data source: Athens Stock Exchange (Athens).

"statistically significant at a $90 \%$ confidence level.

"statistically significant at a $95 \%$ confidence level.

***statistically significant at a $99 \%$ confidence level.

Table 2: Econometric estimation of Model (1) for the Greek stock market.

almost 17 years, which preceded the world financial crisis, the Greek market has had a market anomaly and the returns in December and January were systematically higher compared to returns for the other months of the year. Therefore, within this timeframe the market was inefficient since phenomena were observed that contradict the market efficiency hypothesis.

After the world financial crisis hit at the end of 2007, the market also demonstrated calendar anomalies. Until the beginning of the debt crisis in 2009, the months of March and December indicate statistically significant and higher returns than the other months of the year. The calendar anomaly in December for the realization of higher returns was preserved and the world financial crisis did not have any influence on it. The January anomaly, identified before the crisis, however, did not manifest itself and it was replaced by the anomaly in the month of March. It was probably caused by the negative trend of price drops induced by the crisis which lasted from December (2007) until February (2009) and included two January months with strongly negative returns. As a result the average effect for the month of January decreased. Simultaneously, March (2009) marked the strongest market recovery in the period between the two crises.

When analyzing the entire period from 1991 till 2014, it turns out that the December anomaly was preserved. The 2009 debt crisis, just like the previous financial crisis, did not influence this anomaly. For a period of 24 years, encompassing four full market cycles, and two dramatic crises on the Greek market, a calendar anomaly expressed as the "December effect" was preserved. The stock returns in the month of December were systematically higher by 3.7 percentage points than the mean return for the rest of the months. In other words, the empirical data about the Greek market does not support the hypothesis that it was efficient during the analyzed period.

Table 3 indicates the results for the Bulgarian market. They, however, tell a different story. In the period before the start of the international financial crisis there were market anomalies with regard to four months of the year. In January, June, July, and September there was a statistically significant and higher return compared to the mean return for the rest of the months. The effect was the strongest in the month of June, expressed by 2.7 percentage points higher return, and for the other three months the return was 1.9-2.4 percentage points higher.

After the start of the international financial crisis, these calendar effects disappeared. They did not recover after the debt crisis as well. That is to say that during the years before the crises, it could not be accepted that the Bulgarian market was efficient. There were calendar effects, which contradicts the hypothesis for market efficiency.

At the same time, when the entire period of market development is analyzed, including the period after the crises such effects are not registered. Thus, there is empirical justification to accept that the market efficiency improved because calendar anomalies dropped out. Nevertheless, this conclusion should be taken with a certain degree of attention. The reason is that the time series for the Bulgarian market is significantly shorter than the time series for the Greek one. Therefore, the effect of the crisis periods has more "weight" compared to the other data. Obviously, the low or negative values of returns during the crisis periods have caused a decrease of the otherwise systematically higher returns during specific months within previous periods.

Table 4 indicates the results from the econometric estimation of Model (2) and the testing of the "Halloween effect" hypothesis for the Greek market. For each of the analyzed periods, the values of the estimated coefficients of the model, as well as the standard regression coefficients of the model, the standard errors of the estimation, empirical student's t-statistic are seen, noticed together with the possibility such statistics to be realized, lead to the conclusion that the null hypothesis is true.

As it is seen from the table, during the period preceding the beginning of the international financial crisis and when data for the period following is added, the regression coefficient for DH turns out to be statistically significant at $90 \%$ and $95 \%$ confidence levels, respectively. Therefore, the hypothesis for the lack of the "Halloween effect" during those periods should be rejected.

This result is compatible with the conclusion of Bouman, and Jacobsen [36], who document the availability of the "Halloween effect" 


\begin{tabular}{|c|c|c|c|c|c|c|}
\hline \multirow{2}{*}{ Variable } & \multicolumn{2}{|c|}{ Oct. 2000-Nov. 2007} & \multicolumn{2}{|c|}{ Oct. 2000-Sept. 2009} & \multicolumn{2}{|c|}{ Oct. 2000-Dec. 2014} \\
\hline & Coefficient & t-statistics & Coefficient & t-statistics & Coefficient & t-statistics \\
\hline D1 & $6.3600^{* *}$ & 1.9588 & 0.4288 & 0.1136 & $3.0590^{* *}$ & 1.2120 \\
\hline D2 & 4.1760 & 1.2862 & $2.6005^{*}$ & 0.6890 & 2.5079 & 0.9937 \\
\hline D3 & -3.9705 & -1.2229 & -3.8754 & -1.0268 & -2.5929 & -1.0274 \\
\hline D4 & 1.4625 & 0.4505 & 3.3094 & 0.8768 & 2.1351 & 0.8460 \\
\hline D5 & -0.1741 & -0.0536 & 1.7027 & 0.4511 & $0.7146^{\star *}$ & 0.2832 \\
\hline D6 & $8.7832^{* \star \star}$ & 2.7052 & 5.2277 & 1.3851 & 2.4782 & 0.9819 \\
\hline D7 & $7.7990^{* *}$ & 2.4020 & 4.6995 & 1.2451 & 3.6728 & 1.4552 \\
\hline D8 & 2.5726 & 0.7924 & 5.2089 & 1.3801 & 3.0910 & 1.2247 \\
\hline D9 & $6.6517^{* *}$ & 2.0487 & 3.2678 & 0.8658 & 1.5850 & 0.6280 \\
\hline D10 & 4.9138 & 1.6179 & 0.1574 & 0.0417 & $-1.0120^{* * *}$ & -0.4150 \\
\hline D11 & 2.7698 & 0.9120 & $-0.4481^{*}$ & -0.1187 & -0.8974 & -0.3681 \\
\hline D12 & 3.4792 & 1.0716 & 2.5864 & 0.6853 & 2.3836 & 0.9776 \\
\hline
\end{tabular}

Data source: Bulgarian Stock Exchange (Sofia).

"statistically significant at a $90 \%$ confidence level.

"statistically significant at a $95 \%$ confidence level.

"**tatistically significant at a $99 \%$ confidence level.

Table 3: Econometric estimation of Model (1) for the Bulgarian stock market.

\begin{tabular}{|c|c|c|c|c|}
\hline Periods and Variables & Coefficients & Standard error & t-statistics & $\mathbf{P}$ \\
\hline \multicolumn{5}{|c|}{ Jan. 1991-Nov. 2007} \\
\hline $\mathrm{CO}$ & $0.1647^{*}$ & 0.8589 & 0.1918 & 0.8481 \\
\hline DH & $2.1211^{*}$ & 1.2177 & 1.7418 & 0.0831 \\
\hline \multicolumn{5}{|c|}{ Jan. 1991-Sept. 2009} \\
\hline $\mathrm{CO}$ & -0.3390 & 0.8437 & -0.4018 & 0.6882 \\
\hline DH & $2.4401^{* *}$ & 1.1958 & 2.0406 & 0.0425 \\
\hline \multicolumn{5}{|c|}{ Jan. 1991-Dec. 2014} \\
\hline $\mathrm{CO}$ & -0.5263 & 0.7731 & -0.6808 & 0.4965 \\
\hline DH & $1.7415^{\star \star *}$ & 1.0933 & 1.5929 & 0.1123 \\
\hline
\end{tabular}

Data source: Athens Stock Exchange (Athens).

"statistically significant at a $90 \%$ confidence level.

*statistically significant at a $95 \%$ confidence level.

statistically significant at a $99 \%$ confidence level.

Table 4: Econometric estimation of Model (2) for the Greek stock market.

for the Greek market for an earlier period that ends in 1998. It is also compatible with the results of Siriopoulos, and Giannopoulos [38], who also find this effect within the timeframe from 1986 until 2004. The continuation of the effect after that and its presence even after the end of the international financial crisis indicates how rigid it was.

During the period from 01.1991 till 11.1997, the "Halloween effect" indicates that the monthly return for the six months from November till April was on average 2.12 percentage points above the monthly mean return for the other six months of the year. The effect is similar for the period from 01.1991 till 09.2009 . In this timeframe the monthly return during the six months from November till April was on average 2.44 percentage points above the monthly return for the other six months of the year.

When the results of model (1) are also taken into consideration, it could be argued that the identified "Halloween effect" was mainly caused by the months of January and December for the period from 01.1991 till 11.1997 and by the months of March and December for the period from 01.1991till 09.2009. This result is not compatible with the conclusions of Siriopoulos, and Giannopoulos [38]. They found out that the "Halloween effect" was caused not by a systematic calendar influence of particular months, but rather by separate "unusually" high negative returns during the market crash in October, 1987 and in August, 1998, during the Russian crisis. The results in Table 4 rather support other hypothesis; namely that the largest systematic influence was caused by the monthly effect in December, together with the monthly effects in January and March. All of these months fall within the period November-April and this is the probable cause for the appearance of the "Halloween effect" for the Greek market.

The results in Table 4 also indicate that the hypothesis for the lack of a "Halloween effect" after the start of the debt crisis could not be rejected with a $90 \%$ confidence level. The empirical data is very close to the critical value for rejecting the hypothesis, but, nevertheless, it remains. The market crash caused by the debt crisis, beginning in November 2009 and continuing till May, 2011, reduced and obliterated the otherwise systematically positive "Halloween effect" that was observed before that.

Table 5 shows the results regarding the estimation of Model (2) for the Bulgarian market. As could be seen in this case, the hypothesis for lack of "Halloween effect" could not be rejected with a meaningful confidence level.

In analyzing the seasonal effects by months, it turns out that during 


\begin{tabular}{|c|c|c|c|c|}
\hline Periods and Variables & Coefficients & Standard error & t-statistics & $\mathbf{P}$ \\
\hline \multicolumn{5}{|c|}{ Oct. 2000-Oct. 2007} \\
\hline $\mathrm{CO}$ & 5.0869 & 1.3145 & 3.8699 & 0.0002 \\
\hline $\mathrm{DH}$ & $-2.4323^{*}$ & 1.8700 & -1.3007 & 0.1970 \\
\hline \multicolumn{5}{|c|}{ Jan. 1991-Sept. 2009} \\
\hline $\mathrm{CO}$ & $3.3773^{*}$ & 1.4972 & 2.2558 & 0.0261 \\
\hline $\mathrm{DH}$ & $-2.6104^{* *}$ & 2.1173 & -1.2329 & 0.2203 \\
\hline \multicolumn{5}{|c|}{ Oct. 2000-Dec. 2014} \\
\hline $\mathrm{CO}$ & 1.7224 & 1.0138 & 1.6989 & 0.0912 \\
\hline $\mathrm{DH}$ & $-0.6315^{* * *}$ & 1.4296 & -0.4417 & 0.6593 \\
\hline
\end{tabular}

Data source: Bulgarian Stock Exchange (Sofia).

"statistically significant at a $90 \%$ confidence level.

"*statistically significant at a 95\% confidence level.

"statistically significant at a $99 \%$ confidence level.

Table 5: Econometric estimation of model (2) for the Bulgarian stock market.

the first analyzed period (preceding the international financial crisis) there was a positive calendar effect for the months of January, June, July, and September. Three out of these four months fall out of the period November-April and the higher returns for them hindered the appearance of a possible "Halloween effect".

\section{Discussion}

Traders constantly search for predictable security's price action patterns and affect prices when they attempt to exploit the uprising trading opportunities. Stable forecasting patterns are, therefore, unlikely to persist for long periods of time and will self-destruct when discovered by a large number of traders and speculators. Therefore, this gives rise to non-stationarities in the time series of financial returns and complicates formal tests and evidences of market efficiency, market anomalies and the search for successful forecasting approaches. Hence, the personalized (adaptive) temporal dynamic approaches could improve trading returns by incorporating temporal trading functionalities. Paper's innovation is the introduction and discussion of the temporal trading functionalities encapsulated in markets inefficiency, as far as the calendar market anomalies is concern.

The empirical study of the Greek and the Bulgarian stock markets demonstrates the presence of market anomalies, related to calendar effects. It turns out, that for the Greek market for a period of 24 years (1991-2014), including four full market cycles and two dramatic crises, a calendar anomaly was preserved and was expressed as a "December effect". Stock returns during the month of December were systematically higher compared to the rest of the months of the year. This applies for the time before the 2007 financial crisis and between this crisis and the following 2009 debt crisis, and for the period following it. The two crises did not have any influence on that effect. This conclusion represents a particular interest as far as previous studies on the Greek market have mostly demonstrated the availability of a "January effect".

If one analyzes the period before the two crises on the Greek market (1991-2007), calendar anomalies would be observed for the months of January and December. During a period of almost 17 years, preceding the international financial crisis, the Greek market had had calendar anomalies and returns in December and January were systematically higher compared to the other months of the year. This conclusion and the "January effect" in particular support the results of Fountas, and Segredakis [25], Mills et al. [27], and Koutianoudis, and Wang [28], who find the "January effect" in previous periods, and respectively it does not support Floros (2008) [29], who does not identify such an effect for a previous period as well.

As far as the "Halloween effect" is concerned, the empirical study of the Greek market demonstrates that this effect was also present in the period before the start of the debt crisis. This result is compatible with the conclusions of Bouman, and Jacobsen [36], who also find this effect for an earlier period. The continuation of the effect after that and its presence even after the international financial crisis indicates how rigid it was.

The identified "Halloween effect" is mainly caused by the systematically high returns during the months of January and December for the period from Jan.1991-Nov.1997 and during March and December for the period from Jan.1991-Sep.2009. This result is not compatible with the conclusions of Siriopoulos, and Giannopoulos [38], who believe that the "Halloween effect" on the Greek market is caused not by a systematic calendar influence of particular months, but by particular phenomena; "unusually" large negative returns during the market crash of October, 1987 and of August, 1998 during the Russian crisis.

The conclusions presented above indicate that within the analyzed timeframe the Greek market was inefficient, because empirical evidence had been observed, which contradicts the market efficiency hypothesis. This situation was rigid and the international financial crisis and the debt crisis had had a comparatively low influence on it.

The Bulgarian market shows market anomalies with regard to four months of the year within the period before the start of the international financial crisis. In January, June, July, and September there was a statistically significant higher return in comparison to the other months. The effect was most powerful in the month of June. Or in other words the market hasn't been efficient during this period. This result is consistent with calendar anomalies and seasonality as identified by Stoica, and Diaconasu [40] for the period 2000-2010, by Guidi et al. [41] for the period 1999-2009, and by Tilica, and Oprea for the Romanian stock market (the day-of-the-week effect, DOW) [42] ${ }^{4}$. When data for the period after the start of the international financial crisis is added, these calendar effects disappear, since low returns during the crisis period compensate for the high returns in particular months before it. The monthly calendar effects did not reappear after the debt crisis as well.

The analyzed data does not justify the identification of the "Halloween effect" for the Bulgarian market neither before, nor after the two crises. There were monthly calendar effects before the international financial crisis. At the same time, taking into account the period after the crises such effects could not be registered. Therefore, there might be a formal empirical justification to accept the fact that market efficiency

\footnotetext{
${ }^{4}$ These studies employ daily data which usually show larger random fluctuations.
} 
was improved because the monthly calendar anomalies disappeared. Nevertheless, such a conclusion should be taken with caution since it may not be a correct one. The time series for the Bulgarian market is comparatively short and therefore data for the crisis periods have a lot of "weight" in the data set.

I survey 500 Chief Financial Officers (CFOs) in the Greece and Bulgaria to directly assess whether their firms are credit constrained during the global financial crisis of 2007 and the local south-Europe crisis in 2009. We study whether corporate spending plans differ conditionally on this survey-based measure of financial constraint. Our evidence indicates that constrained firms planned deeper cuts in tech spending, employment, and capital spending. Constrained firms also burned out through more cash, drew more heavily on lines of credit for fear, banks would restrict access in the future, and sold more assets to fund their operations.

Ialso find that the inability to borrow externally caused many firms to bypass attractive investment opportunities, with $72 \%$ of constrained Greek and Bulgarian CFOs claiming that their investment in attractive projects was restricted during the credit crisis of 2007. Also, more than half of the respondents declared that they canceled or postponed their planned investments. This analysis contributes to the portfolio of approaches and adds some knowledge on the impact of financial crises on real firm behavior.

Finally, the presented empirical evidences are in support of the hypothesis that small and less liquid markets tend to exhibit market anomalies [45-47]. For both the Greek and the Bulgarian markets calendar anomalies are identified for the period before the international financial crisis in 2007. Such anomalies may be so strong that they could be stable enough, so that they could not be influenced by deep sovereign crises (the case of Greece). At the same time periods of crisis may change long run calendar anomalies (the case of Bulgaria). Crises usually bring relatively large negative returns which could compensate for systematically higher returns in particular months in previous periods. Such changes may formally lead to the conclusion of the improvement of market efficiency, but this may not be the case. It may just be a short run effect of the crisis while in the long run the relevant market may continue to exhibit anomalies [48-50].

\section{Conclusions}

The main target of this paper is to investigate, analyze and document the trading functionalities enclosed in calendar market anomalies. These functionalities are characterized as temporal because of the "time" function involved by default in calendar market anomalies. In particular the paper is focused on the identification of monthly calendar anomalies on the Greek and Bulgarian stock markets. Empirical evidence, before and after the 2007 and 2009 financial crises, is presented to support the hypothesis that small and less liquid markets tend to exhibit market anomalies.

In the case of Greece these anomalies are so strong that they are not influenced by the recent crises. Empirical evidence show, also, that crises may change the long-run calendar anomalies trading functionalities and therefore could lead to improved market efficiency as a short-run effect. Traders constantly search for predictable security's price action patterns and affect prices when they attempt to exploit the uprising trading opportunities. Stable forecasting patterns are, therefore, unlikely to persist for long periods of time and will selfdestruct when discovered by a large number of traders and speculators. Therefore, this gives rise to non-stationarities in the time series of financial returns and complicates formal tests and evidences of market efficiency, market anomalies and the search for successful forecasting approaches. Hence, the personalized (adaptive) temporal dynamic approaches could improve trading returns by incorporating temporal trading functionalities.

In this paper, I document regularities in trading patterns of individual and institutional investors related to the market anomalies ("Weekend, January, Halloween, November, and December effects"). In particular, we find a relative increase in trading activity by individuals on Mondays. In addition, there is a tendency for individuals to increase the number of sell transactions relatively to buy transactions, which might explain at least part of the "Weekend effect" [42-44].

As paper's innovation could be regarded the introduction and discussion of the personalized (adapted) temporal trading functionalities encapsulated in markets inefficiency, as far as the calendar market anomalies (various "effects") is concern. Actually, the presented analysis improves the existing portfolio of approaches regarding the impact of financial crises on real firm behavior.

\section{Conflicts of Interest}

The author has not declared any conflict of interests with the Greek and Bulgarian stock market data and trading strategies discussed herein. What is presented in the article is as balanced, unbiased, objective and evidence-based as possible.

\section{Author's Bio Profile}

Vasiliki A. Basdekidou holds a B.Sc. degree in Economics from the Aristotle University of Thessaloniki (Greece, 2002), a two-year master's degree in Economics (major: Financial Economics) from the University of Macedonia (Greece, 2005) and a Ph.D. in Corporate Finance from the Bulgarian Academy of Sciences - Economic Research Institute (Bulgaria, 2015). She is working at the Special Research Fund Account of the Aristotle University of Thessaloniki for the last 10 years.

\section{References}

1. Malkiel BG (2003) The Efficient Market Hypothesis and Its Critics. Journal of Economic Perspectives 17: 59-82.

2. Timmermann A, Granger CWJ (2004) Efficient Market Hypothesis and Forecasting. International Journal of Forecasting 20: 15-27.

3. Laffont JJ, Maskin ES (1990) The Efficient Market Hypothesis and Insider Trading on the Stock Market. Journal of Political Economy 98: 70-93.

4. Branson C, Duffy B, Perry C, Wellings D (2012) Acceptable behaviour: Public opinion on behaviour change policy. London: Ipsos MORI.

5. Camerer CF (2003) Behavioral game theory. Princeton, NJ: Princeton University Press.

6. Camerer CF, Loewenstein G, Rabin M (2011) Advances in Behavioral Economics. Princeton, NJ: Princeton University Press.

7. Basdekidou VA (2015) Functionality, Returns and Efficiency before and after the Debt Crisis: An Empirical Analysis of the Greek Stock Market (Unpublished doctoral dissertation). Bulgarian Academy of Sciences - Economic Research Institute, Bulgaria.

8. Chiraz A (2016) Does the Index Futures Destabilize the Underlying Spo Market? Some Evidence from Frensh Stock Exchange. Bus Eco J 7: 244.

9. Agrawal A, Tandon K (1994) Anomalies or Illusions? Evidence from Stock Markets in Eighteen Countries. Journal of International Money and Finance 13: 83-106.

10. Basdekidou VA (2016) IPO Trading with Short-term and Intraday Temporal Functionalities. Bus Eco J 7: 257.

11. Basdekidou VA (2017) Seasoned Equity Offerings as Technical Market 
Citation: Basdekidou VA (2016) Personalized Temporal Trading Functionalities Engaged in Calendar Market Anomalies: Empirical Evidences from the 2007 and 2009 Financial Crises. J Bus Fin Aff 5: 225. doi: 10.4172/2167-0234.1000225

Page 10 of 10

Anomalies: Long-term Temporal Trading Functionalities. International Journal of Economics and Finance 9(1)

12. Basdekidou VA (2016) Nonfarm Employment Report Trading with Binary Options and Temporal Functionalities. Annales Universitatis Apulensis series Oeconomica 18(2).

13. Basdekidou VA, Styliadou AA (2017) Technical Market Anomalies: Leveraged ETF Trading with Daily and Intraday Temporal Functionalities. Bus Eco J 8: 275

14. Rozeff M, Kenney W (1976) Capital Market Seasonality: The Case of Stock Returns. Journal of Financial Economics 3: 379-402.

15. Keim DB (1983) Size-Related Anomalies and Stock Return Seasonality: Further Empirical Evcidence. Journal of Financial Economics 12: 13-32.

16. Kato K, Schallhaim JS (1985) Seasonal and Size Anomalies in the Japanese Stock Market. Journal of Financial and Quantitative Analysis 20: 243-260.

17. Berges A, McConnell JJ, Schlarbaum GG (1984) The Turn-of-the-Year in Canada. Journal of Finance 39: 185-192.

18. Nassir A, Mohammad S 91987) The January Effect of Stocks Traded on the Kuala Lumpur Stock Exchange: An Empirical Analysis. Hong-Kong Journal of Business Management 5

19. Balaban E (1995) January Effect, Yes! What About Mark Twain Effect? Discussion Papers, 9509, Central Bank of the Republic of Turkey.

20. Nassar S (2016) The impact of capital structure on Financial Performance of the firms: Evidence From Borsa Istanbul. J Bus Fin Aff 5: 173

21. Kabeer MA, Iqbal A, Najaf K, Najaf R (2016) The Influences of MacroEconomic Factors on Capital Market Performance in Pakistan. J Bus Fin Aff 5: 176.

22. Asteriou D, Kovetsos G (2006) Testing for the Existence of the January Effect in Transition Economies. Applied Financial Economic Letters 2: 375-381.

23. Davcev L, Hourvouliades N (2013) The Influence of the Greek Economic Crisis on FYROM Exports. J Bus Fin Aff 3: 115.

24. Asiedu E (2016) A Study of use and Impact of Market Segmentation Practices on Bank Performance: With Special Reference to Commercial Banks in Colombia. J Bus Fin Aff 5: 162.

25. Fountas S, Segredakis KN (2002) Emerging Stock Markets Return Seasonalities: The January Effect and Tax-loss Selling Hypothesis. Applied Financial Economics 12: 291-299.

26. Maghyereh Al (2003) Seasonality and January Effect Anomalies in an Emerging Capital Market. The Arab Bank Review 5: 25-32.

27. Mills TC, Siriopoulos C, Markellos RN, Harizanis D (2000) Seasonality in the Athens Stock Exchange. Applied Economics Letters 10: 137-142.

28. Koutianoudis T, Wang S (2003) Is the January Effect Economically Exploitable? Evidence from Athens Stock Exchange. Working Paper, University of Manchester.

29. Floros C (2008) The Monthly and Trading Month Effects in Greek Stock Marke Returns: 1996-2002. Managerial Finance 34: 453-464.

30. Corhay A, Hawaini P, Michel P (1987) Seasonality in the Risk-Return Relationshp: Some International Evidence. Journal of Finance 42.

31. Marret G, Worthington A (2011) The Month of the Year Effect in the Australian Stock Market: A Short Technical Note on the Market, Industry and Firm Size Impacts. Australian Accounting Business and Finance Journal 5.

32. Dash M, Dutta A, Sabharwal M (2011) Seasonality and Market Crashes in Indian Stock Markets. Asian Journal of Finance and Accounting 3.

33. Bhabra H, Dhillon U, Ramirez R (1999) A November Effect? Revisiting the TaxLoss-Selling Hypothesis, Financial Management 28: 5-15.
34. Geske R, Subrahmanyam A, Zhou Y (2016) Capital structure effects on the prices of equity call options. Journal of Financial Economics 121: 231-253.

35. Johnston K, Paul C (2005) Further evidence of the November effect. Journal of Economics and Finance 29: 280-288.

36. Bouman S, Jacobsen B (2002) The Halloween Indicator, Sell in May and Go Away: Another Puzzle. American Economic Review 92: 1618-1635.

37. Andrade SC, Chhaochharia V, Fuerst ME (2012) Sell in May and Go Away Just Won't Go Away. Financial Analysts Journal 69: 94-105.

38. Siriopoulos C, Giannopoulos P (2006) Market Efficiency in the Greek Stock Exchange: The Halloween Effect. SPOUDAI, University of Pireus 56: 75-88.

39. Kamstra M, Kramer LA, Levi MD (2003) Winter Blues: Seasonal Affective Disorder (SAD) and Stock Market Returns. American Economic Review 93: 324-343.

40. Stoica O, Diaconasu DE (2011) An Examination of the Calendar Anomalies on Emerging Central and Eastern European Stock Markets: Recent Researches in Applied Economics. Proceedings of the $3^{\text {rd }}$ World Multiconference on Applied Economics, Business and Development (AEBD '11), lasi, Romania, 16-121.

41. Guidi F, Gupta R, Maheshwari S (2010) Weak-form Market efficiency and calendar anomalies for Eastern Europe equity Markets. MPRA.

42. Tilica EV, Oprea D (2014) Seasonality in the Romanian Stock Market: The dayof-the-Week Effect. Procedia Economics and Finance 15: 704-710.

43. Alexakis $P$, Xanthakis M (2006) Day-of-the-Week Effect on the Greek Stock Market. Applied Financial Economics 5: 43-50.

44. Ajayi RA, Mehdian S, Perry MJ (2014) The Day-of-the-Week Effect in Stock Returns: Further Evidences from Eastern European Emerging Markets Emerging Markets Finance and Trade 40: 53-62.

45. Hossain SA (2015) An Empirical Analysis to Assess the Impact of Inconsistency of Exchange Rate on Share Market: A Case Study of London Stock Exchange. J Bus Fin Aff 4: 154

46. Athanassakos G (2014) Is Volatility Risk? The Bad Influence of Academia to the Discussion. J Bus Fin Aff 3: 127.

47. Najaf R, Najaf K (2016) Impact of Crude Oil Prices on the Bombay Stock Exchange. J Bus Fin Aff 5: 216.

48. Gurloveleen K, Bhatia BS (2015) An Impact of Macroeconomic Variables on the functioning of Indian Stock Market: A Study of Manufacturing Firms of BSE500. J Stock Forex Trad 5: 160

49. Vargas-Hernandez JG, Echeagaray JES, Echeagaray TIS (2016) Analysis of the Organizational Eco-Systemic Change in a Cooperative Society of Fishing Production. Bus Eco J 7: 230

50. Jarrett JE, Li Y (2016) A Data Analytical Study of the Japanese Equity Market over a Lengthy Period. Bus Eco J 7: 241. 